\title{
Copulatory behavior of male hamsters as a function of time since androgen withdrawal'
}

\author{
B. N. BUNNELL AND CAROL K. FLESHER \\ UNIIERSITY OF FLORIDA
}

\begin{abstract}
The copulatory behavior of three groups of sexually experienced male hamsters was observed after androgen withdrawal. Each group was given four tests spaced five days apart: Group I began 45 days, Group II 60 days, and Group III 75 days after hormone removal. Amount of copulatory activity was found to be similar for all groups. In experienced males, the reduction of sexual behavior following androgen withdrawal may involve an active extinction process.
\end{abstract}

\section{Problem}

It is apparent that copulatory experience can potentiate the postcastration sexual behavior of male hamsters. Bunnell \& Kimmel (1965) found that sexually experienced males (11 trials totalling 65 min.) show more copulatory activity after castration than less experienced animals (two trials totalling $20 \mathrm{~min}$.); these animals ceased copulating 42 days after castration. Flesher (1964) castrated highly experienced (four trials totalling 120 min.) hamsters and waited 45 days before initiating postoperative testing. These castrates all copulated. Seven of nine mounted, and four achieved intromissions within $5 \mathrm{~min}$. on their first postoperative test (Bunnell and Kimmel used 5-min. tests). All were still mounting 80 days after castration, although only two were making intromissions.

The relationship between time since castration and persistence of copulatory behavior was explored further by withdrawing testicular hormones from three groups of highly experienced hamsters. Testing was initiated at a different time for each group in order to separate the effects of time since hormone withdrawal from the effects of the experience received during testing.

\section{Method}

Eighteen male golden hamsters, approximately 300 days of age, were maintained on ad lib lab chow and water, supplemented by cereals and greens. Housing was in individual cages in an air conditioned room with a normal 12-hr. light-dark cycle. They averaged $584 \mathrm{~min}$. of copulatory experience each before the present experiment began. Estrus was induced in the ovariectomized stimulus females by injecting $.10 \mathrm{mg}$ estradiol $75 \mathrm{hr}$., and $1.0 \mathrm{mg}$ progesterone $3 \mathrm{hr}$., before testing.

The plexiglass test chamber was 12 in high and 19 in in diameter, and was mounted on a glass base. A mirror below the base of the chamber facilitated observations.

Three matched groups were formed on the basis of the average number of intromissions each animal made on four pre-experimental trials. Nine of the animals were castrates which had been maintained on exogenous androgen since gonadectomy, the other nine were intact. Three animals of each type were assigned to each group. Hormone withdrawal was accomplished by castrating the intact males and terminating the androgen injections of the other animals.

Group I animals had a delay of 45 days between hormone withdrawal and the first experimental test, Group II was delayed 60 days, and Group III 75 days. Each Group was given four trials spaced five days apart. In this fashion, the fourth test for Group I coincided with the first test for Group II, and the fourth test for Group II coincided with the first test for Group III.

Testing was done at night, beginning after 9:30 p.m. A male was placed in the apparatus for a 5-min. adaptation period. The female was then introduced and copulatory behavior recorded for $20 \mathrm{~min}$.

\section{Results and Discussion}

Several behavioral categories were scored, but only mounts (both "mounts" and "partial intromissions" as defined by Beach \& Rabedeau, 1959), intromissions (Beach and Rabedeau's "complete intromissions"), and a combined score, the sum of mounts and intromissions, are reported here. While an intromission always involved mounting, a mount was scored only when the animal failed to achieve an intromission after mounting. The combined score was used to give an indication of an animal's level of excitability.

All animals copulated on the post-withdrawal tests (there were no differences between those which had been on replacement therapy before the experiment began and those which had been intact). Table 1 gives the percentage of animals in each group that responded with a latency of less than $5 \mathrm{~min}$. Data from Flesher's (1964) study are also included. Although direct com-

TABLE I

Posthormone Testing: Percentage of Animals in Each Group Giving Mounts (M), and Intromissions (I) with a Latency of Less than Five Minutes

Flesher's (1964) Data Included for Comparison

\begin{tabular}{cccccc} 
& & Test 1 & Test 2 & Test 3 & Test 4 \\
\hline Group I & $M$ & 100 & 100 & 67 & 67 \\
$N=6$ & I & 50 & 50 & 50 & 33 \\
\hline Group II & $M$ & 83 & 67 & 100 & 50 \\
$N=6$ & I & 67 & 33 & 100 & 33 \\
\hline Group III & $M$ & 100 & 100 & 83 & 67 \\
N=6 & I & 67 & 50 & 67 & 33 \\
\hline Flesher & $M$ & 78 & 67 & 33 & 44 \\
N=9 & I & 33 & 33 & 11 & 11
\end{tabular}




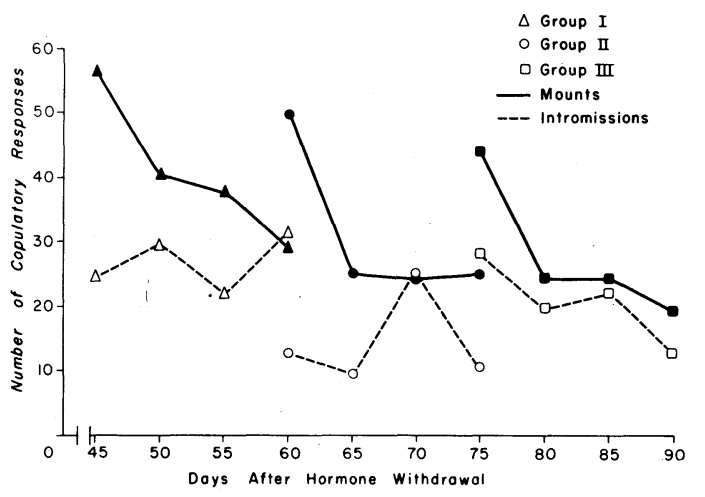

Fig. 1. Mean copulatory performance for four tests of three groups of hamsters as a function of days after hormone withdrawal.

parisons are not possible, it is apparent that the performance of these highly experienced animals exceeded that of animals which had less experience prior to hormone withdrawal. The Bunnell \& Kimmel (1965) animals had stopped responding 42 days after hormone withdrawal. Flesher's more experienced animals continued to respond, but not as well as the highly sophisticated animals in the present study. Amount of copulatory experience is an important factor in the de ofee of preservation of both mounts and intromissions in castrated hamsters.

The performance of all animals on the first postwithdrawal test was compared with their performance during the first 20 min. of their last test prior to withdrawal. A Wileoxon test of the combincd scores measure was not significant $(T-46.5, N-17, p-.05)$ suggesting that sexual excitement was undiminished. However, intromissions were reduced ( $T$ 26.5, $\mathrm{N}: 18$, $\mathrm{p}<.01)$. Despite this difference, it was found that two animals in Group I, one in Group II, and two in Group III had an increased Imlromis sion score on the first test after hormone withdrawal. In general, then, experience is less effective in preserving intromissions than mounts: however, the overall decline in intromissions is subject to large increases in variability. Thos: marked individual differences support Aronson's (1961) contention that different types of postcastration behavior patterns, similar to those found for cats, may be identifiable in lower species, including hamsters.

Analyses of variance of the raw scores on all three measures showed that Group (time since hormone withdrawal) effect was not significant on any measure but that the Tests main effect was significant for mounls ( $\mathrm{F}=78.3$, df $3 / 45, \mathrm{p}<01)$ and for combincd siori $(f=11.2$, df $3 / 45, \mathrm{p}<.01)$.

The Neuman-Keuls procedure (Winer, 1962) showed that, for mounts, the first test of each group was significantly different from the three that followed, but that these three did not differ from each other.
The main effect for Tests was not significant on the intromission score. The Groups $\mathrm{x}$ Tests interaction was not significant on any measure. The curves for mounts and intromissions are plotted in Fig. 1.

Too few tests were conducted for complete extinction of sexual responses, but within the limits of the testing schedule, the groups are not really distinguishable. On any test $(1,2,3$, or 4$)$ there is more similarity between groups than there is within groups over tests. This suggests that it may be necessary for experienced animals to make copulatory responses before sexual behavior is eliminated.

The mechanism by which copulatory experience potentiates sexual behavior in castrated males remains obscure. Beach (e.g., 1958) has suggested that such experience could help to sensitize a sexual arousal mechanism (AM) and thus lower the threshold for copulatory responses. The sudden drop in performance on the second test for all groups might be equivalent to a desensitization of the "cortical" portion of the AM (or perhaps to the extinction of an acquired approach drive). The level, or slowly dropping subsequent performance, might be more closely related to a physiologic capacity for responding which reflects residual sensitization of the "subcortical" AM or, perhaps, the state of the reproductive tract.

In the later case, however, the evidence is that secondary peripheral changes following castration either should have been complete (Ortiz, 1953) or uninfluential (Pauker, 1948). The possibility exists that hormones and experience interact to produce changes in the reproductive tract such that the regression of some structure crucial to successful copulation is either slowed or prevented.

\section{References}

Ironson. I. R. Hormones and reproductive behavior Some phyloafenetio comsiderations In A Gorbman i Ed). ('omparative endermoleren Now York: Wilery, 1961

Beach, I I Neural and chemical regulation of behavior In H, F

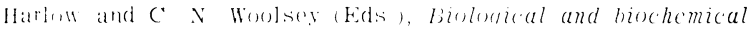

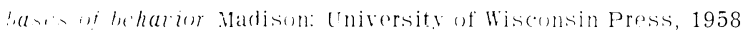

Boach. I. I.. \& Babedeau. R. G. Sexual exhaustion and recovery in the male lamster J. (c)mp. physiol. Psychol. 1959. 52, 56-61. Bunnell. B. N. \& Kimmel. Mary F. Effects of copulatory experinene wh putcastration mating behavior in the male hamster P.

Fesher. carol K. Stimulus-hormone interartion and the gampractic behavior of the male Syrian golden hamster Unpublishod dis. tiral disicurtation, University of Florida, August, 1964.

ortiz. Novina. The effects of castration on the reproductive sis tem of the golden hamster Anat. Rec., 1953, 117, 65-92.

Pauker R \& The effects of removing seminal vesicles, prostate and : ("istes on the mating behavior of the golden hamster, cri cthe aurutus, J comp). physios. Psychol., 1948, 41, 252-257.

Winer. 13. J. Statistical principles in experimental desian. Now York: HeCiraw-Hi]l, 1962

\section{Note}

1 Supported by National Science Foundation Grant NSF GB-1149 to the senior author The work was conducted while the jumior author Was un Public Health Sorvice Fellowship MH 17,436. 